Árboles y Rizomas Vol. III, Nº 1 (enero-junio, 2021): 40-56

Universidad de Santiago de Chile, ISSN 0719-9805

https://doi.org/ 10.35588/ayr.v3i1.4970

\title{
Uso de oraciones subordinadas en el discurso narrativo escrito de estudiantes de enseñanza básica ${ }^{1}$
}

\author{
Use of subordinated sentences in the written narrative discourse by elementary \\ students
}

\author{
Claudia Araya, Sergio Aravena, Dayanne Cifuentes, Sofía Gaete, Vanessa López, Consuelo \\ Sepúlveda ${ }^{2}$
}

\section{Resumen}

La investigación describe la complejidad sintáctica en un corpus narrativo escrito de estudiantes de $3^{\circ}, 5^{\circ}$ y $7^{\circ}$ básico en dos tipos de establecimiento educacional. Se busca caracterizar las oraciones en términos de su complejidad (número, uso de oraciones simples y subordinadas, y tipos de oraciones subordinadas empleadas) en los niveles escolares estudiados. Además, se indaga si es que se aprecian diferencias entre los establecimientos educacionales. Respecto a este último punto, no se apreciaron diferencias. Por otra parte, los resultados muestran un desarrollo sostenido en términos de la cantidad de oraciones subordinadas y una disminución en el uso de oraciones simples que se producen de un nivel escolar al siguiente. En cuanto a los tipos de oraciones subordinadas, se observa un mayor uso de oraciones subordinadas sustantivas (realizadas, en su mayoría, a través de verbos en infinitivo) y de oraciones subordinadas adverbiales de tiempo, modo y causa por sobre los otros tipos de oraciones. Se concluye que se podría apoyar los procesos de complejización del discurso narrativo mediante un foco no solo centrado en la enseñanza de estrategias particulares de producción de este tipo de discurso en términos superestructurales, sino también acompañado por modelos de producción sintáctica de complejidad creciente.

Palabras clave: desarrollo sintáctico, oraciones subordinadas, escritura, escolaridad.

\begin{abstract}
This study describes the syntactic complexity in a corpus of written narratives by 3rd, 5th and 7th grade students in two types of schools. It seeks to characterize the sentences used in terms of their complexity: number, use of simple and (types of) subordinate sentences in each of the school levels studied. In addition, it studies whether there are differences between the types of school. Regarding this last point, there were no differences of any kind. On the other hand, the results show a sustained development in terms of the number of subordinate sentences and a decrease in the use of simple sentences produced from one school level to the next. Regarding the types of subordinate sentences, there is a greater use of nominal subordinate sentences (using infinitive verbs) and of adverbial subordinate sentences of time, mode and cause over other types of sentences. It is concluded that the complexity of narrative discourse could be assisted through a
\end{abstract}

\footnotetext{
${ }^{1}$ Resultado de grupo de investigación, Carrera de Fonoaudiología, Universidad de Chile.

${ }^{2}$ Departamento de Fonoaudiología, Facultad de Medicina, Universidad de Chile. carayac@uchile.cl, ORCID ID: https://orcid.org/0000-0001-8639-6584
}

Recibido: 18/05/2021

Aceptado: 16/06/2021 
focus not only on teaching particular strategies for the production of this type of discourse in superstructural terms, but also by modeling syntactic production in growing degrees of complexity.

Keywords: syntactic development, subordinate sentences, writing, schooling.

\section{Introducción}

La escritura es una competencia básica y fundamental para la comunicación y la participación en sociedad. En este sentido, el manejo del lenguaje escrito es una habilidad considerada indispensable en el desarrollo del pensamiento y en el aprendizaje (Aguilar, Albarrán, Errázuriz y Lagos, 2016). Puesto que es una forma compleja de actividad analítica, la escritura permite la toma de conciencia de la persona que escribe acerca de la construcción lógica de las ideas que plantea de forma escrita (Montealegre y Forero, 2006).

El aprendizaje de esta habilidad durante la niñez implica la apropiación de un determinado sistema de signos y símbolos, cuyo manejo marca un momento crucial en el desarrollo cultural del niño (Vygotski, 1931/1995). Por otra parte, desde una perspectiva cognitiva, la integración de estas habilidades implica una alta demanda para la memoria de trabajo y, puesto que este tipo de memoria es limitada, este proceso depende en gran medida del grado de automatización de las tareas implicadas en la escritura para su buen funcionamiento (Berninger et al., 1992; Sánchez, Moyano y Borzone, 2011). Por otra parte, además de la maduración cognitiva, participan en la consolidación de la escritura factores como la psicomotricidad y el establecimiento de la lateralidad (Pozo, 2010).

Si bien el lenguaje escrito comienza a ejercitarse a edades tempranas, su desarrollo formal se da principalmente dentro del aula durante la educación primaria. En relación a la enseñanza formal del lenguaje escrito, el Ministerio de Educación de Chile es el encargado de elaborar y entregar las Bases Curriculares para los establecimientos educacionales chilenos desde la educación parvularia. A partir de este nivel educativo, se fomenta un trabajo inicial de acercamiento a los textos escritos que les permita a los y las estudiantes el acceso a ambientes alfabetizados con una mediación adecuada (Subsecretaría de Educación Parvularia, 2018). En cuanto a las habilidades que permiten el desarrollo del lenguaje escrito en los primeros años de escolaridad, se entregan contenidos que apoyan la adquisición de la conciencia fonológica y gráfica, incorporando los recursos y convenciones propias del eje escritura desde el comienzo de la enseñanza básica (Equipo de Desarrollo Curricular, 2020).

Los contenidos específicos involucrados en el desarrollo del eje escritura en la escuela comprenden un trabajo enfocado en la enseñanza de múltiples habilidades de forma simultánea. En general, un adecuado desempeño escritural debiese reflejarse en una creciente capacidad de utilizar el vocabulario, la estructura textual y la ortografía (Smith-Lock, Nickels \& Mortensen, 2009). Estas habilidades lingüísticas forman parte de los siete subsistemas, dependientes entre sí, que han sido descritos para representar el manejo de la escritura en español: la gramática, la puntuación, el acento ortográfico, la separación de las palabras, la coherencia y la composición, tanto gráfica como ortográfica (Matute, Chamorro, González, Guajardo e Inozemtseva, 2014). Con respecto a la ortografía, su enseñanza ha sido considerada un aspecto prioritario en la escolarización básica. De acuerdo a las distintas etapas del desarrollo en que se encuentran los y las estudiantes, muchos de los errores tendrán sentido durante el proceso de aprendizaje, ya que se considera que son parte del proceso de desarrollo de las regularidades del código gráfico (Camps et al., 2007). El riesgo de equivocación en el proceso de escritura no radicaría en el conocimiento o desconocimiento que se tenga sobre sus convenciones, sino en la conciencia de la posibilidad de 
error (Salgado, 1997). Un aspecto beneficioso en este tipo de conciencia, sería la motivación que surgiría de buscar información que permita subsanar la falta, lo que, a su vez, conduciría a una instrumentalización de dicha información, por medio de la revisión y corrección de la propia escritura. De este modo, se lograría un mayor conocimiento del código escrito, que podrá ser útil en otras situaciones (Díaz y Cabeza, 2012).

Desde una perspectiva semántica, el desarrollo de la escritura se relaciona, además, con la creciente habilidad de elaborar textos que cumplan con ciertas normas de "buena formación textual". Dichas normas se establecen bajo los principios de cohesión y coherencia, los que están intrínsecamente entrelazados. De esta manera, una de las propiedades fundamental de cualquier texto es la coherencia, que se refiere al significado de un texto a nivel semántico y pragmático, mientras que la cohesión es un fenómeno asociado a las relaciones particulares y locales que se establecen entre distintos elementos lingüísticos en los textos (Calsamiglia y Tusón, 1999). En esta misma perspectiva, la cohesión sería equivalente a una "sintaxis textual" (Bernárdez, 1993).

El manejo de las características de coherencia y cohesión de los textos se relaciona directamente con el tipo de género discursivo bajo estudio. Los géneros discursivos corresponden a productos culturales en los que el uso verbal es un elemento fundamental (Calsamiglia y Tusón, 1999). Según Hasan (1984), el texto es la expresión verbal de una actividad social, en la que los factores relevantes del ambiente están relacionados causalmente con los elementos de la estructura del texto. Por su parte, los textos pertenecen a tipos textuales, que pueden estar definidos a partir de sus características internas (verbales), externas (pragmáticas), o a partir de una combinación de ambas (Loureda, 2017).

El desarrollo de la habilidad de producir diferentes tipos de textos de manera cohesiva y coherente es uno de los principales objetivos del sistema escolar (Peña y Quintero, 2016). Uno de los tipos de texto con que se trabaja en la educación primaria corresponde al texto narrativo. En este tipo de texto, se presenta un curso de eventos que se construye y desenvuelve como una serie de episodios. Cada uno de estos episodios se va desarrollando paso a paso a partir de una secuencia de figuras unidas por medio de conectores temporales (Halliday y Matthiessen, 2004). En términos de estructura y contenido, el texto narrativo consiste, por lo tanto, en un conjunto de oraciones coherentemente organizadas, en las que se hace referencia a eventos que se relacionan tanto causal como temporalmente, y en donde se presenta un conflicto con su posterior resolución (Bassols y Torrent, 1997). Específicamente, el cuento infantil se estructura en tres categorías formales básicas: presentación, episodio y final. En la presentación se incluye el personaje con sus atributos, la ubicación temporal y espacial, además del evento inicial que genera el relato. En el episodio, por su parte, se encuentran las acciones y los estados de los personajes, algunos obstáculos para llegar a la meta y sus resultados. Por último, en el final se resuelve el problema planteado en la presentación (Pavez, Coloma y Maggiolo, 2008).

Se entregan a continuación algunos antecedentes bibliográficos y conceptuales acerca del estudio de la escritura y la narración en escolares, además de algunas definiciones sobre oraciones subordinadas y complejidad sintáctica. En el apartado de metodología se explican las características del corpus, la manera en que se segmentó el corpus y el plan de análisis, para finalizar con la discusión de los resultados y las conclusiones de este trabajo.

\section{El estudio de la escritura y la narración en escolares}

El estudio de la escritura en la última década ha estado centrado, principalmente, en el ámbito de la escritura académica. Las investigaciones existentes acerca de la escritura en escolares se concentran más en el proceso de escritura y en la identificación de prácticas de enseñanzas 
efectivas, que en la exploración sistemática de las características lingüísticas de la producción escrita a lo largo de la educación básica (Rubio, 2016).

Respecto a los estudios de escritura escolar, se han encontrado estudios sobre escritura narrativa cuyo objetivo ha sido conocer y describir la producción de narraciones según criterios, por ejemplo, de coherencia y cohesión y de adecuación en el uso de la superestructura narrativa. Al respecto, se ha sugerido que los estudiantes cuentan con un escaso repertorio de recursos cohesivos tales como conectores y correferencias, incluso en $7 \mathrm{mo}$ básico, y que tienen, además, internalizada una estructura narrativa básica (Sotomayor et al., 2013). Textos narrativos producidos por niños que cursaban tercero básico en colegios municipalizados y subvencionados también mostraron una adecuación respecto a la producción de una superestructura narrativa. Sin embargo, se aprecia una falta de claridad en el orden de los eventos presentados, debido a la falta de uso de conectores adecuados. Por otra parte, tampoco utilizan la subordinación de ideas como recurso cohesivo, lo que redunda en un uso excesivo de la conjunción 'y' Benítez (2009). Por otra parte, Meneses, Ow y Benítez (2012) establecieron que las producciones escritas y orales de escolares mostraban distintos índices de complejidad de acuerdo a las distintas fases secuenciales encontradas dentro de sus textos narrativos. En esta misma línea, Peñaloza (2008) observó que los porcentajes de aparición de oraciones subordinadas son distintos en las distintas fases de recontados narrativos de niños de seis, ocho y diez años, y que dichas proporciones se mantenían relativamente estables en las distintas edades. De hecho, se ha establecido que los fines retóricos y de significado que se plasman en cada fase de una secuencia discursiva seleccionan un conjunto más o menos diferenciado de recursos sintácticos, entre ellos, distintos tipos de subordinadas (Benítez y Alvarado, 2013).

En relación a la complejidad sintáctica en narraciones escritas por escolares, se ha observado un uso predominante de complejos clausulares por sobre el uso de cláusulas simples en $3^{\circ}, 5^{\circ}$ y $7^{\circ}$ básico. Desde una perspectiva del desarrollo, se aprecia también una diferencia significativa entre el $3^{\circ}$ y el $5^{\circ}$ nivel en relación al incremento de las relaciones hipotácticas que se establecen entre las cláusulas del corpus analizado, lo que se interpreta como un fenómeno de condensación de información dentro de una misma estructura sintagmática (Rubio, 2020). A partir del análisis de narraciones orales de niños y niñas de $3^{\circ}$ y $5^{\circ}$ básico, Coloma, Peñaloza y Fernández (2007) establecieron que existe un desarrollo de la complejidad sintáctica en términos del uso de una mayor cantidad de cláusulas adjetivas y sustantivas de un nivel educativo al otro. En niveles educativos inferiores (preescolar y primero básico), también se constata un aumento de la complejidad sintáctica en recontados narrativos orales de un curso al siguiente, específicamente, aumenta el índice de densidad clausular dentro de las oraciones complejas y el número de subordinadas sustantivas en las etapas narrativas de presentación y final (Peñaloza, Araya y Coloma, 2017). También se ha encontrado en las narraciones orales de niños y niñas preescolares una mayor complejidad sintáctica en los esquemas causales de la historia y en las manifestaciones del mundo interno de los personajes (Crespo, Koza y Sotelo, 2017).

\section{Oraciones subordinadas y complejidad sintáctica}

Las investigaciones sobre complejidad sintáctica permiten reconocer el nivel de manejo de determinadas estructuras a medida que aumenta la edad y el nivel escolar de los y las hablantes. En la descripción de dicha complejidad, es posible posicionarse desde distintas perspectivas teóricas, lo que implica también el surgimiento de unidades, métodos e instrumentos específicos para analizar el desarrollo sintáctico (Crespo, Alfaro y Góngora, 2011). Por ejemplo, desde la perspectiva de la diversidad interclausular, el uso de una mayor cantidad de formas para relacionar 
cláusulas se ha establecido como una evidencia del desarrollo de la sintaxis oral en escolares de distintos niveles educativos (Crespo, Alvarado y Meneses, 2013). Por otro lado, según Auza y Alarcón (2011), la complejidad sintáctica corresponde a la capacidad de relacionar dos o más unidades predicativas verbales bajo criterios de gramaticalidad y coherencia. Desde esta perspectiva, en un niño o niña en desarrollo, la capacidad de utilizar sintaxis compleja daría cuenta de una creciente habilidad de ajuste, tanto en la forma como del contenido, de lo que este o esta desea expresar de acuerdo a sus necesidades comunicativas.

Desde una perspectiva estructural, puede entenderse la complejidad sintáctica como la mayor presencia de oraciones subordinadas por sobre el uso de oraciones simples o compuestas. Por su parte, el concepto de sintaxis compleja ha sido utilizado para describir aquellas construcciones oracionales en que uno o más verbos se subordinan a un verbo principal (Gili Gaya, 1948; Real Academia Española, 2010). Así, la oración compleja se conforma por un verbo principal y uno o más subordinados, mientras que las oraciones subordinadas se forman a partir de un verbo subordinado junto al resto de los constituyentes de la construcción. Las oraciones subordinadas suelen denominarse de acuerdo a su función dentro de la predicación principal y a su forma. De esta manera, se reconocen tres grandes tipos de subordinadas: las de relativo, las nominales y las llamadas adverbiales. Las oraciones subordinadas adverbiales pueden ser propiamente adverbiales, como las de lugar, tiempo y modo, que cuentan con un equivalente funcional adverbial en cada caso, y otras construcciones subordinadas, sin dicho equivalente, como las causales, finales y concesivas (Real Academia Española, 2010).

Frente a la necesidad de contar con mayor información acerca de las características lingüísticas que poseen los textos narrativos escritos por estudiantes de enseñanza básica, se plantea el estudio de los tipos de oraciones presentes en un corpus de narraciones escritas con el fin de aportar a la investigación acerca de los mecanismos de complejización sintáctica que utilizan estudiantes de enseñanza básica en sus textos a medida que avanzan en su nivel escolar.

\section{Metodología}

Esta investigación es un estudio descriptivo que se enmarca en un paradigma cuantitativo, con un diseño no experimental transeccional. Tiene como objetivo identificar los tipos de oraciones presentes en el corpus narrativo escrito de 180 estudiantes de $3^{\circ}, 5^{\circ}$ y $7^{\circ}$ básico provenientes de dos tipos de establecimientos educacionales: un colegio municipal (CM) de nivel socioeconómico medio-bajo, ubicado en la comuna de Estación Central, y un colegio particular subvencionado (CPS), de nivel socioeconómico medio-alto, de la comuna de Santiago. Se obtuvo, así, 180 textos que se desglosan como se aprecia en el Cuadro 1:

Cuadro 1. Desglose del corpus de estudio

\begin{tabular}{|l|l|l|}
\hline & Colegio Municipal & $\begin{array}{l}\text { Colegio Particular } \\
\text { Subvencionado }\end{array}$ \\
\hline 3ro básico & 30 & 30 \\
\hline 5to básico & 30 & 30 \\
\hline 7mo básico & 30 & 30 \\
\hline Total & 180 textos \\
\hline
\end{tabular}

El corpus fue obtenido de una tarea de escritura guiada por imágenes como parte de una actividad en la asignatura de Lenguaje y Comunicación, para la cual los participantes contaron con 
un tiempo de 80 minutos. Dicha tarea forma parte del proyecto Fondecyt/iniciación 11130010 "Desarrollo de la producción escrita en escolares básicos: un análisis desde la lingüística sistémico funcional" y fue facilitado por el investigador responsable para la realización del presente estudio desde otra perspectiva teórica y metodológica. Cada texto fue identificado con un código, que sintetiza la información acerca del tipo de establecimiento educacional al que pertenece cada estudiante (CM o CPS), el curso, las iniciales de su nombre y su sexo.

El estímulo para la escritura de la tarea consistió en una serie de imágenes que fueron presentadas en formato PPT. Los criterios de selección de esta narración en imágenes en particular fueron que los protagonistas de la historia son una niña y un niño de edad similar a la de los escolares de enseñanza básica que realizaron la tarea, por lo tanto, podrían identificarse con ellos. Por otra parte, las imágenes eran suficientemente explícitas para poder permitir la construcción potencial de diferentes relatos y recursos retóricos (Rubio, 2016).

Se contó con el consentimiento informado de los apoderados acerca de la participación de los estudiantes en esta investigación y con la autorización de profesores de cada curso, como también del director de cada establecimiento educativo. En todos los casos, se aseguró la confidencialidad de los datos y su uso solo con fines académicos.

\section{Segmentación del corpus y plan de análisis}

Se agregó los 180 textos a una planilla Excel y se segmentó cada uno de ellos en oraciones. Para efectos de esta investigación, se definió la oración como una unidad mínima de predicación en la que se relacionan sujeto y predicado (Real Academia Española, 2010). Cada una de estas oraciones se clasificó de acuerdo al criterio "oración simple" y "oración compleja", como se define a continuación.

- Oración Simple: oración que cuenta con un núcleo predicativo sin verbos que se encuentren subordinados (Pavez et al., 2015). Por ejemplo: "Juan se combirtio en una piedra" (CM-3B$\mathrm{VC}-1 \mathrm{~F})$.

- Oración Compleja: construcciones en que uno o más verbos se subordinan a un verbo principal (Gili Gaya, 1948; Real Academia Española, 2010). Por ejemplo: "cuando Jose la abrazo le dijo con cariño a Daniela que nunca peliaran y que fueran a casa” (CM-7B-AF-23M).

A su vez, por cada oración compleja, se contabilizó el número de oraciones subordinadas (OS) por oración. La definición de oración subordinada es la siguiente:

- Oración Subordinada (OS): Oraciones que dependen de la oración principal o se encuentra integrada en uno de sus elementos constitutivos (Real Academia Española, 2010). Por ejemplo: "un dia salieron a otra parte porque sus papas los echaron a la calle" (CPS-5B-CM-9F).

Por último, cada oración subordinada fue clasificada de acuerdo a tres grandes tipos de oraciones, que aquí hemos denominado: adjetivas, sustantivas, y las llamadas adverbiales. Estas últimas reúnen una diversa gama de construcciones subordinadas, algunas propiamente adverbiales, como las locativas, y otras sin equivalente funcional adverbial, como las concesivas (Real Academia Española, 2010). Cada una de ellas se define, para propósitos de este estudio, de la siguiente manera:

- Oración Subordinada Adjetiva: son las oraciones que ejecutan las funciones propias de un sintagma adjetivo (Real Academia Española, 2010). Por ejemplo: "y vio una casa que brillava" (CPS-3B- SE-6F).

- Oración Subordinada Sustantiva: oraciones que ejecutan las funciones propias de un sintagma o grupo nominal (Real Academia Española, 2010). Por ejemplo: “a Star le gustaba leer” (CM5B-CL-22M). 


\section{Claudia Araya, S. Aravena, D. Cifuentes, S. Gaete, V. López, C. Sepúlveda}

- Oración Subordinada Adverbial: oraciones que cumplen con las funciones propias de un sintagma adverbial (Real Academia Española, 2010). Por ejemplo: "y Emily se quedo en casa leyendo un libro" (CPS-7B-JL-8F).

Finalmente, se sub-clasificó las oraciones sustantivas y adverbiales de acuerdo a su forma y/o función. De esta manera, desde una perspectiva funcional, se reconoció oraciones subordinadas sustantivas declarativas, que presentan el verbo en una forma personal (con la conjunción subordinante "que" más una oración que constituye su término) o no personal (como el infinitivo en "espero aprobar el curso"). También desde una perspectiva de la función, se reconoció oraciones subordinadas interrogativas indirectas, que formalmente se presentan con un pronombre interrogativo ("no sé qué decir") o con la conjunción "si" (No sé si decirle"). Por último, se reconoció como sustantivas a las oraciones que, en su forma, no presentan un antecedente expreso (Real Academia Española, 2010).

En el caso de las oraciones subordinadas adverbiales, se reconoció aquellas que son propiamente adverbiales en su función (lugar, tiempo y modo) y las sin equivalente funcional adverbial (concesión, condición, finalidad, consecución y causa). La Tabla 1 muestra un ejemplo de segmentación y análisis:

Tabla 1. Ejemplo de segmentación y análisis del corpus

\begin{tabular}{|c|c|c|c|c|c|c|c|}
\hline \multirow{2}{*}{ Ejemplos del corpus } & \multirow{2}{*}{ Complejidad } & \multirow{2}{*}{$\begin{array}{l}\text { Total OS por } \\
\text { oración }\end{array}$} & \multicolumn{3}{|c|}{ Oración subordinada } & \multicolumn{2}{|c|}{ Tipo Oración subordinada } \\
\hline & & & Adjetiva & Sustantiva & Adverbial & Sustantiva & Adverbial \\
\hline $\begin{array}{l}\text { "y la hermana supo que cuando uno } \\
\text { ama al otro puede consegir lo que } \\
\text { quiere si le tiene confiansa al otro" } \\
\text { (CM-5B-DM-2F) }\end{array}$ & Compleja & 4 & 0 & 2 & 2 & $\begin{array}{l}\text { - Conjunción "que" } \\
\text { - Oración sin } \\
\text { antecedente expreso }\end{array}$ & $\begin{array}{l}\text {-Tiempo } \\
\text {-Condición }\end{array}$ \\
\hline $\begin{array}{l}\text { "Cuando ya era de noche todos } \\
\text { se fueron a dormir menos valentina } \\
\text { por que valentina queria darle } \\
\text { una broma a su hermano David } \\
\text { al asustarlo" (CM-5B-CQ-11F) }\end{array}$ & Compleja & 4 & 0 & 2 & 2 & $\begin{array}{l}\text { - Infinitivo } \\
\text { - Infinitivo }\end{array}$ & $\begin{array}{l}\text {-Tiempo } \\
\text {-Causa }\end{array}$ \\
\hline $\begin{array}{l}\text { "y el hermano le prometio disculparse } \\
\text { con el señor para que les bolbiera } \\
\text { a prestar el cuarto" (CPS-5B-MB-14F) }\end{array}$ & Compleja & 2 & 0 & 1 & 1 & - Infinitivo & -Finalidad \\
\hline $\begin{array}{l}\text { "beia figuras en los árboles asta } \\
\text { que encontró a su hermano mayor } \\
\text { combertido en estuata } \\
\text { por que toca a un hongo que estaba } \\
\text { echizado" (CM-5B-GG-19M) }\end{array}$ & Compleja & 3 & 1 & 0 & 2 & - & $\begin{array}{l}\text {-Tiempo } \\
\text {-Causa }\end{array}$ \\
\hline $\begin{array}{l}\text { "nos persige un cocodrilo" } \\
\text { (CM-3B-MS-14M) }\end{array}$ & Simple & - & - & - & |- & - & - \\
\hline $\begin{array}{l}\text { "y encuentran un túnel" } \\
\text { (CPS-7B-CF-1F) }\end{array}$ & Simple & - & |- & - & |- & - & - \\
\hline
\end{tabular}


Los datos resultantes fueron resumidos y organizados en tablas de contingencia de tres entradas. Posteriormente, se efectuaron pruebas chi-cuadrado de Pearson para determinar la existencia de asociación entre los tipos de oraciones, el año cursado y los tipos de colegios (Solano et al., 2007). Puesto que el estadístico chi-cuadrado de Pearson sólo permite contrastar una hipótesis general de independencia entre las variables de una tabla de contingencia, se obtuvieron, además, los residuos tipificados corregidos para cada cruce de variables con el fin de observar los resultados en mayor detalle. Por otra parte, no se realizó pruebas de chi-cuadrado en el caso de las tablas de contingencia en las que alguna celda tuviera una frecuencia esperada inferior a 5. En su lugar, se realizaron gráficos para poder visualizar las diferencias arrojadas por el análisis de los subtipos de oraciones subordinadas (sustantivas y adverbiales) en ambos establecimientos educacionales.

Todos los análisis estadísticos fueron realizados con el software R (R Core Team, 2020). Respecto a la significatividad estadística, se consideran como estadísticamente significativos valores de residuales de Pearson inferiores a -2 superiores a 2.

\section{Análisis y discusión}

El objetivo de este estudio fue describir el tipo de oraciones utilizadas en el corpus narrativo escrito de estudiantes de $3^{\circ}, 5^{\circ}$ y $7^{\circ}$ básico en dos tipos de establecimientos educacionales. En primer lugar, no se encontró ninguna diferencia estadísticamente significativa respecto a la aparición del total de oraciones y de tipos de oraciones en ambos tipos de establecimientos educacionales. Estos resultados se aprecian en la Tabla 2. Aquí se observa que el rango de significatividad del total de oraciones corresponde a 0.57 y -0.53 , es decir, que no existe una diferencia estadísticamente significativa entre los datos analizados y, por lo tanto, los textos producidos en ambos tipos de colegios no se distinguen en función de la cantidad de oraciones utilizadas en la producción de oraciones en la tarea de escritura realizada. Por otra parte, los tipos de oraciones subordinadas presentes en los textos en ambos tipos de colegios tampoco se diferencian en términos estadísticos: el rango de las oraciones subordinadas sustantivas fue de 0.72 y -0.72 , y el de las oraciones subordinadas adverbiales, de 0.23 y -0.23 . No se realizó un análisis estadístico de los tipos de oraciones subordinadas adjetivas, puesto que el número de casos fue muy bajo.

La similitud de resultados para ambos tipos de establecimientos va en línea con los hallazgos de Benítez y Sotelo (2013), quienes tampoco hallaron diferencias en la calidad de las oraciones producidas por estudiantes de un colegio particular subvencionado y uno municipal. Del mismo modo, se ha observado que ni la estructura textual de dos tipos de narraciones ni los tipos de cláusulas utilizadas en ellas muestran diferencias significativas de acuerdo a la variable tipo de establecimiento (Rubio, 2016, 2019).

Tabla 2. Comparación entre colegio municipal y particular subvencionado

\begin{tabular}{|l|l|l|}
\hline \multicolumn{3}{|c|}{ Rango de Residual de Pearson } \\
\hline $\begin{array}{l}\text { Significatividad entre } \\
\text { total de Oraciones }\end{array}$ & $\begin{array}{l}\text { Significatividad entre OS } \\
\text { Sustantivas }\end{array}$ & $\begin{array}{l}\text { Significatividad entre } \\
\text { OS Adverbiales }\end{array}$ \\
\hline 0.57 y -0.53 & 0.72 y -0.72 & 0.23 y -0.23 \\
\hline
\end{tabular}


Respecto a la diferencia entre oraciones simples y complejas (ver Tabla 3), se aprecia una diferencia significativa en el uso de este tipo de oraciones en dos niveles educativos, 3ro y 7mo básico. Los resultados más destacables al respecto son dos: en primer lugar, se aprecia, en 3ro básico, independientemente del tipo de establecimiento, un uso significativamente menor de oraciones complejas (CM -3.3; CPS -3.6) en comparación al desempeño observable en el resto de los cursos. En segundo lugar, es posible también advertir una diferencia estadísticamente significativa respecto al mayor uso de oraciones complejas en $7 \mathrm{mo}$ básico en ambos tipos de colegio (CM 3.9; CPS 2.8).

Tabla 3. Comparación de la significatividad entre oraciones simples y complejas

\begin{tabular}{|l|l|l|l|}
\hline \multicolumn{1}{|c|}{ Establecimiento } & Curso & Complejas & Simples \\
\hline Colegio Municipal & $3^{\circ}$ Básico & $-3.3^{*}$ & 0.8 \\
\cline { 2 - 5 } & $5^{\circ}$ Básico & -1 & 0.2 \\
\cline { 2 - 5 } & $7^{\circ}$ Básico & $3.9^{*}$ & -1 \\
\hline Colegio Particular Subvencionado & $3^{\circ}$ Básico & $-3.6^{*}$ & $3.8^{*}$ \\
\cline { 2 - 5 } & $5^{\circ}$ Básico & -0.3 & 0.6 \\
\cline { 2 - 5 } & $7^{\circ}$ Básico & $2.8^{*}$ & $-3.4^{*}$ \\
\hline
\end{tabular}

Estos resultados apuntan directamente al desarrollo de la complejidad sintáctica, en términos de un mayor uso de oraciones subordinadas, asociado al paso de un nivel educacional al otro. Como se señaló anteriormente, esto es especialmente observable cuando se considera 3ro básico y 7 mo básico, como se aprecia en la Tabla 3. En ambos tipos de establecimientos, se evidencia una creciente significatividad positiva para las oraciones complejas, mientras que para las oraciones simples se aprecia una significatividad decreciente. En otro análisis de estos textos escritos, informado por Rubio (2020), se aprecia un patrón de incremento significativo similar en las relaciones hipotácticas presentes en los textos de estudiantes de 3ro y 5 to básico. Asimismo, en textos orales, se ha reportado un mayor desempeño en la complejidad sintáctica en el discurso narrativo de niños y niñas, que avanza tanto con la edad como con los niveles de escolaridad (Gutiérrez-Clellen y Hoffstetter, 1994; Coloma, Peñaloza y Fernández, 2007), hallazgo que también se ha podido observar en textos expositivos (Meneses y Ow, 2016).

En cuanto al resultado relacionado con el tipo de oraciones subordinadas presentes en este corpus narrativo escrito, se aprecia que, en 3ro básico, el número de oraciones subordinadas es bajo en todos los tipos de subordinadas (ver Tabla 4). Este resultado concuerda con los hallazgos de Gutiérrez-Clellen y Hoffstetter (1994) respecto a la tendencia observada en los niveles escolares menores de evitar el uso de sintaxis compleja en sus narraciones. Sin embargo, si se observa el desarrollo prospectivo hacia 5to y $7 \mathrm{mo}$ básico, se advierte que la producción de oraciones subordinadas adjetivas permanece más o menos estable, y en un número mucho menor que la producción de oraciones subordinadas sustantivas y adverbiales en 5 to y 7 mo básico. 


\section{Claudia Araya, S. Aravena, D. Cifuentes, S. Gaete, V. López, C. Sepúlveda}

\section{Oraciones subordinadas adjetivas}

Respecto al uso de oraciones subordinadas adjetivas en contextos narrativos orales, se ha observado que son utilizadas para describir objetos por función, para indicar la identidad de los referentes y, en un grado mayor de dificultad, para presentar información referencialmente compleja (Gutiérrez-Clellen y Hoffstetter, 1994). También se ha buscado una explicación del uso de este tipo de oraciones subordinadas desde una perspectiva funcional discursiva. De acuerdo a esta postura, cada categoría funcional dentro de la estructura narrativa (presentación, episodios, final, etc.) moviliza ciertos recursos sintácticos afines (Meneses et al., 2012). De esta manera, las oraciones subordinadas adjetivas o de relativo cumplirían la función de presentación de personajes en el discurso narrativo que cumplen (Peñaloza, Araya y Coloma, 2017) o función de presentación de la situación narrativa, que sería un uso observable de este tipo de estructuras desde los niveles iniciales de escolarización (Ow y Alvarado, 2013). Esto quiere decir que la aparición de oraciones subordinadas adjetivas o de relativo estaría directamente relacionada con una función discursiva específica dentro de la narración (presentación de personajes y situaciones; ver ejemplos 1 y 2) y que, por lo tanto, se entiende que su prevalencia será más baja que los otros dos tipos de oraciones subordinadas, cuyas funciones sintácticas se extienden a lo largo de todo el texto narrativo.

1) "Abia una vez unos hermanos que eran mui felices" (CM-3B-AB-7F)

2) "descubrieron un túnel que estava muy oscuro" (CM-3B-RS-6M)

Tabla 4. Comparación del número y significatividad entre tipos de oraciones subordinadas

\begin{tabular}{|c|c|c|c|c|c|c|c|}
\hline \multirow[b]{2}{*}{ Establecimiento } & \multirow[b]{2}{*}{ Curso } & \multicolumn{2}{|c|}{ Adjetivas } & \multicolumn{2}{|c|}{ Adverbiales } & \multicolumn{2}{|c|}{ Sustantivas } \\
\hline & & $\mathrm{N}^{\circ}$ & $* \operatorname{sig}$ & $\mathrm{N}^{\circ}$ & $*$ sig. & $\mathrm{N}^{\circ}$ & $*$ sig. \\
\hline \multirow[t]{3}{*}{ Colegio Municipal } & $3^{\circ}$ Básico & 24 & 1.8 & 44 & -0.3 & 58 & -0.3 \\
\hline & $5^{\circ}$ Básico & 24 & -1.3 & 85 & -0.3 & 117 & 0.2 \\
\hline & $7^{\circ}$ Básico & 38 & -1.5 & 140 & 0.4 & 188 & 0.8 \\
\hline \multirow[t]{3}{*}{ Colegio Particular subvencionado } & $3^{\circ}$ Básico & 32 & $3.4^{*}$ & 49 & -0.1 & 48 & $-2.1 *$ \\
\hline & $5^{\circ}$ Básico & 39 & 0.9 & 96 & 0.2 & 123 & 0 \\
\hline & $7^{\circ}$ Básico & 43 & -1.3 & 145 & -0.1 & 195 & 0.4 \\
\hline
\end{tabular}

\section{Oraciones subordinadas sustantivas}

Respecto a la producción de oraciones subordinadas adverbiales y sustantivas, solo se aprecia un valor significativamente menor en el uso de oraciones subordinadas sustantivas en 3ro básico del CPS. Según Ow y Alvarado (2013), la subordinación sustantiva sería más tardía en aparición y de 
mayor complejidad que ciertas subordinaciones adverbiales, lo que podría explicar este resultado. Sin embargo, los textos escritos de 5to y 7 mo básico muestran un desempeño mayor en la producción de estos dos tipos de oraciones subordinadas, que crecen exponencialmente con el paso de un nivel educativo al próximo. Los resultados de nuestro estudio sobre tipos de oraciones subordinadas son consistentes con los hallazgos encontrados en recontados narrativos de niños preescolares y escolares (Coloma, Peñaloza y Fernández, 2007; Peñaloza, Araya y Coloma, 2017). En estos textos narrativos orales, se encontró que las oraciones subordinadas que aparecen con mayor frecuencia en el corpus analizado son las adverbiales y sustantivas.

En términos generales, las oraciones subordinadas sustantivas, oraciones que cumplen las funciones propias de un sintagma o grupo nominal (Real Academia Española, 2010), son la estructura que se presenta en mayor número, y con un crecimiento sostenido, en los tres niveles escolares estudiados. Ya que no se observan diferencias significativas, excepto en 3ro básico del CPS, se interpreta esta progresión como una expresión de creciente complejidad en el uso de elementos nominales. Similarmente, el estudio de Peñaloza, Araya y Coloma (2017) encontró un aumento significativo de las subordinadas sustantivas, en narraciones orales, al relacionarlas con el total de oraciones complejas (oraciones con una o más oraciones subordinadas dentro).

Un estudio más detallado de los subtipos de oraciones subordinadas sustantivas utilizadas en el corpus de estudio permite observar algunos patrones en la complejidad del uso de estructuras nominales. Los resultados descriptivos que se presentan en la Figura muestran la distribución de subtipos de oraciones subordinadas sustantivas, de acuerdo a su forma y/o función: aquellas marcadas por un verbo en infinitivo, por un pronombre interrogativo, por la conjunción "que" o "si" y oraciones sin antecedente expreso.

Figura 1. OS sustantivas por subtipo en $3^{\circ}, 5^{\circ}$ y $7^{\circ}$ básico de ambos establecimientos educacionales

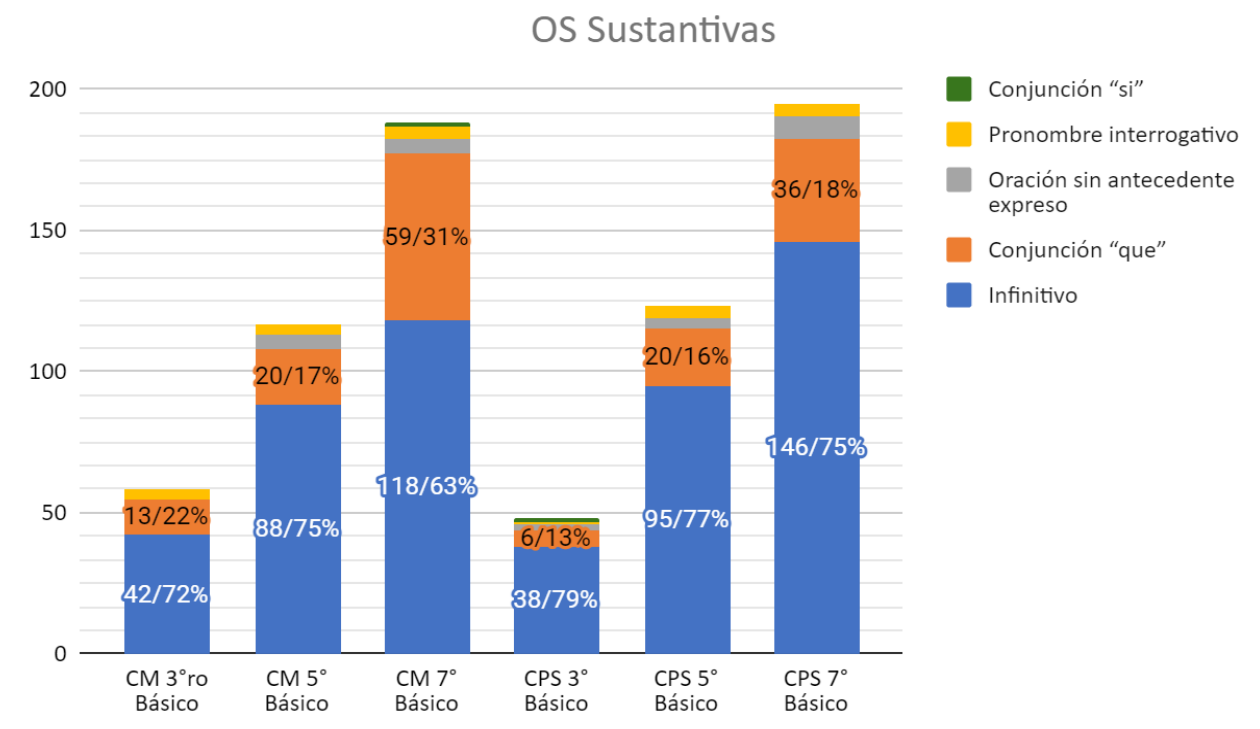

En relación a los resultados por subtipo de oración subordinada se observa que existe un patrón similar respecto a los principales subtipos producidos en todos los niveles escolares. Como se puede apreciar en la Figura 1, el subtipo predominante es la oración subordinada sustantiva expresada a través de una oración con un verbo en infinitivo. Estas representan en general más del $70 \%$ de oraciones subordinadas sustantivas. Considérense los ejemplos 3 y 4: 


\section{3) "y Abraham invito a jugar a la pelota a tres amigos". (CM-3B-BO-3F)}

4) "Su hermano Jose le gustaba jugar a la pelota". (CM-3B-AB-7F)

Gutiérrez-Clellen y Hoffstetter (1994) dan cuenta de un patrón similar de uso de las cláusulas de infinitivo en las narraciones orales de niños y niñas hispanohablantes. En atención a estos resultados y a los de la presente investigación en narraciones escritas, se puede interpretar que este tipo de estructuras con un núcleo verbal en infinitivo forma parte del repertorio sintáctico disponible en niños y niñas en etapa escolar para construir textos narrativos, sean estos orales o escritos, por su menor complejidad gramatical.

En segundo lugar, los resultados también muestran un uso importante de oraciones subordinadas sustantivas con la conjunción "que". Un estudio a partir de los recontados de niños y niñas de 3ro y 5to básico de Coloma, Peñaloza y Fernández (2007) mostró que en 3ro básico los sujetos producían los relatos de los personajes de los cuentos de forma directa mediante oraciones yuxtapuestas (ejemplo 5), mientras que en 5to básico lo hacían de manera indirecta mediante cláusulas sustantivas de subjunción "que" (ejemplo 6). Este tipo de cambios estructurales en la manera de expresar el contenido de las narraciones puede explicar, del mismo modo, el aumento de este tipo de oraciones subordinadas sustantivas en nuestro corpus.

5) "y le digimos degenos entra" (CM-3B-MS-14M)

6) "Amanda le dijo a Tomas que ya era hora de hirse" (CM-7B-IL-9M)

\section{Oraciones subordinadas adverbiales}

El uso de oraciones subordinadas adverbiales también mostró un patrón sistemático de aparición creciente en los tres niveles escolares estudiados y en ambos tipos de establecimientos educativos, como se puede apreciar en el Figura 2.

Los subtipos de oraciones subordinadas adverbiales predominantes fueron las adverbiales de tiempo, modo y causa. Cabe destacar que, dentro de estos tres tipos, las oraciones subordinadas adverbiales de tiempo y modo corresponden a oraciones propiamente adverbiales, es decir, que son intercambiables por adverbios con dichas funciones (tiempo = entonces; modo $=$ así), mientras que la construcción causal no posee un equivalente funcional adverbial. Pavez, Coloma y Maggiolo (2008) encontraron que una correlación entre el desarrollo narrativo (definido con parámetros formales) se corresponde con un mayor uso de relaciones de coherencia causal, temporal y de finalidad en el discurso narrativo oral niños y niñas escolares, lo que es, en general, coherente con nuestros resultados respecto a la información temporal y causal encontrada. En otra muestra de narraciones orales en niños y niñas hispanohablantes, se encontró un orden de aparición de subordinadas adverbiales también similar al nuestro: tiempo, finalidad, causa, modo y lugar (Gutiérrez-Clellen y Hoffstetter, 1994). Las diferencias que se aprecian entre una investigación y otra deben interpretarse de acuerdo a las características de las narraciones involucradas en las tareas solicitadas. De hecho, las narraciones que se produjeron en la tarea de escritura de nuestro estudio muestran una relación directa entre los tipos de vínculos adverbiales que se desprenden de los eventos sugeridos por las imágenes de estímulo y su realización lingüística por medio de oraciones subordinadas adverbiales de diverso tipo. 
Figura 2. OS adverbiales por subtipo en $3^{\circ}, 5^{\circ}$ y $7^{\circ}$ básico de ambos establecimientos educacionales

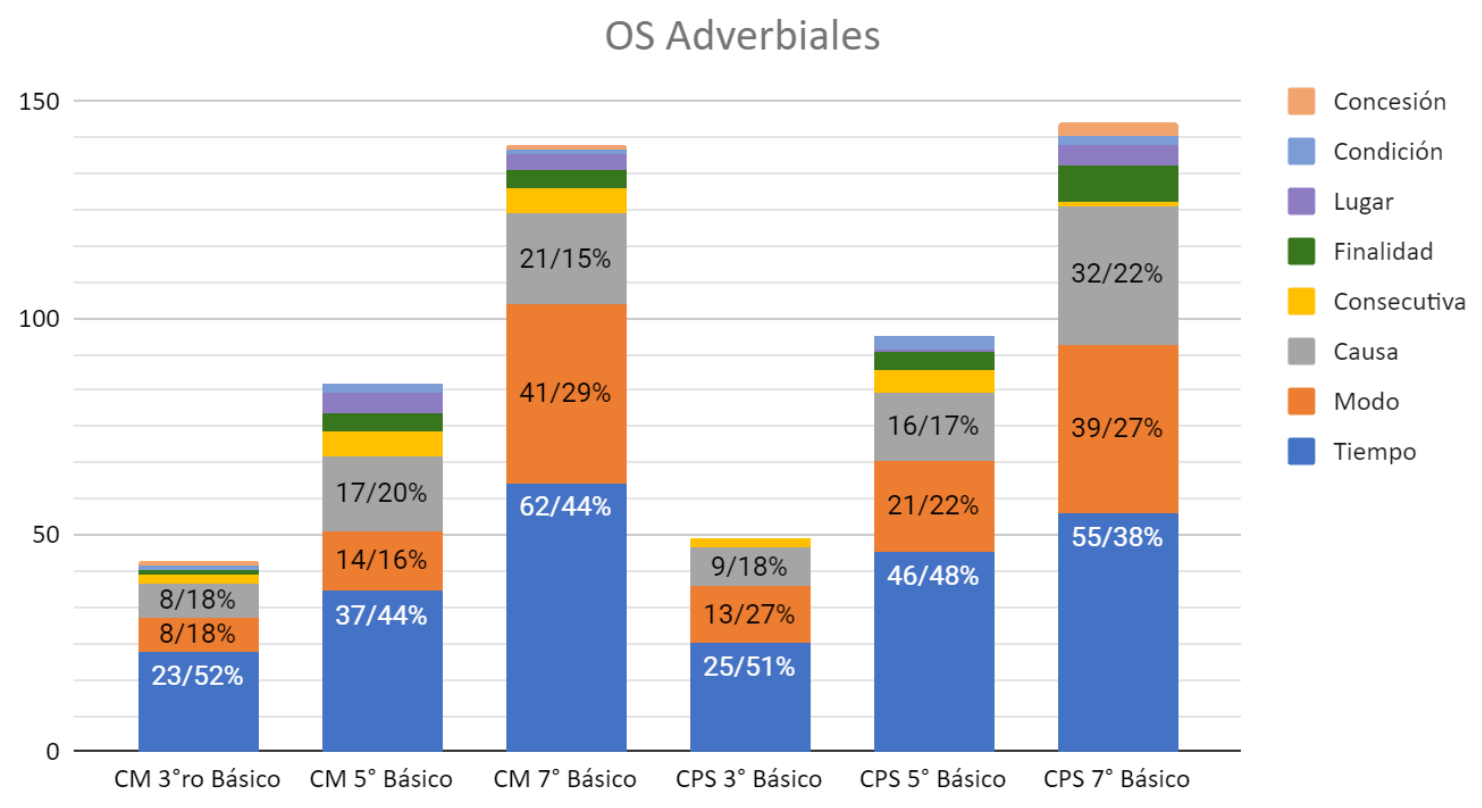

Finalmente, respecto al uso oraciones subordinadas adverbiales, se podría plantear que cada una secuencias narrativas que constituyen un relato se construyen de acuerdo a ciertos patrones funcionales, en este caso, de naturaleza adverbial, que movilizan los recursos sintácticos necesarios para expresar dichos contenidos (Meneses et al., 2012).

\section{Conclusión}

El objetivo de este trabajo fue describir el desarrollo de la complejidad sintáctica en el discurso narrativo escrito de niños y niñas de $3^{\circ}, 5^{\circ}$ y $7^{\circ}$ básico en dos tipos de establecimientos educacionales, a partir de una tarea de escritura producida con apoyo de imágenes. A partir de los resultados, se puede concluir que:

1. No existen diferencias asociadas a los tipos de establecimientos educacionales.

2. Existen diferencias significativas entre niveles educativos en el uso de oraciones simples y complejas. Puntualmente, se observa un significativamente menor número de oraciones complejas en 3ro básico y significantemente mayor en 7mo. De manera inversamente proporcional, el uso de oraciones simples decrece. Se concluye que el desarrollo es constante y sostenido y que se relaciona con el mayor uso de oraciones complejas y menor uso de oraciones simples.

3. Las oraciones subordinadas adjetivas aparecen en un número significativamente menor que las oraciones sustantivas y adverbiales, probablemente por su función discursiva acotada a la presentación de personajes y situaciones.

4. Las oraciones subordinadas sustantivas son el tipo de subordinadas más utilizado en el corpus completo en todos los niveles educativos. Destaca el hecho de que más del $70 \%$ de estas construcciones se realicen mediante un verbo en su forma infinitiva, seguidas de las oraciones subordinadas sustantivas con la subjunción "que". De esta manera, se puede concluir que se opta por la forma más simple de construir subordinación sustantiva mediante el uso de una forma no personal del verbo (infinitivo). 
5. Las oraciones subordinadas adverbiales también tienen una importante presencia en el corpus narrativo analizado. Las principales relaciones adverbiales utilizadas, en orden de relevancia, son de tiempo, modo y causa, lo que coincide con las relaciones de coherencia adverbial encontradas en otros estudios de discurso narrativo en niños y niñas.

Desde una perspectiva disciplinar, esta investigación aporta al estudio de la escritura en escolares con una descripción sistemática de mecanismos de complejización sintáctica de las oraciones que utilizan estudiantes de $3^{\circ}, 5^{\circ}$ y $7^{\circ}$ básico y del manejo de determinadas estructuras a medida que aumenta la edad y el nivel escolar en una muestra de discurso narrativo escrito. Además, permite realizar algunas observaciones respecto al tipo de oraciones que aparecen en la producción de texto narrativo escrito en escolares en una tarea guiada por imágenes en comparación con los resultados encontrados en la producción de textos narrativos orales en niños de la misma edad. Sin embargo, no podemos determinar el efecto de la tarea en los resultados, puesto que no contamos con un corpus de contraste para realizar una comparación. En este sentido, una proyección de este estudio sería el análisis de una muestra de discurso narrativo oral a partir de los mismos estímulos visuales en escolares de las mismas edades y de los mismos establecimientos escolares, con el objetivo de comparar el impacto de la variable oralidad/escritura en los resultados.

Desde una perspectiva curricular, se podría establecer que el desempeño similar de niños y niñas en ambos tipos de establecimientos educativos da cuenta, en términos globales, de que se cumple con el propósito principal del eje escritura en la escuela, que es desarrollar la capacidad expresiva y comunicativa del alumnado en consideración a las condiciones y requerimientos, tanto sociales como culturales, que enmarcan toda la etapa educativa (Equipo de Desarrollo Curricular, 2020).

Por último, desde una perspectiva de la intervención educativa, se podría apoyar los procesos de complejización del discurso narrativo mediante un foco no solo en la enseñanza de estrategias particulares de producción de este tipo de discurso en términos superestructurales, sino que también acompañado por modelos de producción sintáctica de complejidad creciente. Una instrucción explícita sobre los mecanismos gramaticales que permiten la expresión de las causas y consecuencias de las cosas o la importancia de expresar las circunstancias de tiempo, lugar y modo en que se realizan diversos eventos, por ejemplo, representaría una oportunidad de ampliar el repertorio narrativo y gramatical en la escuela. 


\section{Referencias}

Aguilar, P., Albarrán, P., Errázuriz, M. y Lagos, C. (2016). Teorías implícitas sobre los procesos de escritura: Relación de las concepciones de estudiantes de Pedagogía Básica con la calidad de sus textos. Estudios pedagógicos (Valdivia) 42(3), 7-26. https://dx.doi.org/10.4067/S0718-07052016000400001

Auza, A. y Alarcón, L. (2011). Cláusulas subordinadas y coordinadas en dos tareas narrativas producidas por niños mexicanos de primero de primaria. La lengua, lugar de encuentro. Congreso Internacional de la ALFAL. Alcalá de Henares, España.

Bassols, M., y Torrent, A. (1997). Modelos textuales, Teoría y práctica. Barcelona: Octaedro.

Benítez, R. (2009). Análisis descriptivo de narraciones escritas por niños y niñas de tercer año $\begin{array}{lllll}\text { básico. Literatura } \quad y \quad \text { Lingüística } & \text { 20, }\end{array}$ https://doi.org/10.29344/0717621x.20.1565

Benítez, R. y Alvarado, C. (2013). Un análisis descriptivo de la arquitectura sintáctica en la $\begin{array}{llll}\text { oralidad. } & \text { Foro educacional } & 22, & 13-30 .\end{array}$ https://doi.org/10.29344/07180772.22.663

Benítez, R., y Sotelo, E. (2013). Calidad De La Producción Escrita En Dos Secuencias Textuales Según Tipo De Establecimiento Educacional. Logos: Revista De Lingüística, Filosofía Y Literatura 23(2), $127-150$. https://doi.org/10.15443/230201

Bernández, E. (1993). La coherencia textual como autorregulación en el proceso comunicativo. Boletín de Filología 34(1), 9-32.

Berninger, V., Yates, C., Cartwright, A., Rutberg, J., Remy, E. and Abbott, R. (1992). Lower-level developmental skills in beginning writing. Reading and Writing 4, 257-280.

Calsamiglia, H. y Tusón, A. (1999). Las cosas del decir: Manual de análisis del discurso. Barcelona: Ariel.

Camps, A., Milian, M., Bigas, M., Camps, M., y Cabré, P. (2007). La enseñanza de la ortografía. Barcelona: Graó.

Coloma, C., Peñaloza, C. y Fernández, R. (2007). Producción de oraciones complejas en niños de 8 y 10 años. Revista de Lingüística Teórica y Aplicada, 45(1), 33-44. http://dx.doi.org/10.4067/S0718-48832007000100003

Crespo, N., Alfaro, P. y Góngora, B. (2011). La medición de la sintaxis: evolución de un concepto. Onomazein, 24(2), 155-172.

Crespo, N., Alvarado, C. y Meneses, A. (2013). Desarrollo sintáctico: una medición a partir de la diversidad clausular. Logos 23(1),80-101

Crespo, N., Koza, W., y Sotelo, E. (2017). Complejidad sintáctica y construcción de narración. Análisis de una tarea de recontado en niños de preescolar. Círculo de Lingüística Aplicada a la Comunicación, 69-91. https://doi.org/10.5209/CLAC.55315

Díaz, M., y Cabeza, A. (2012). Fases y evolución de la conciencia ortográfica infantil. Docencia e Investigación, (22), 97-114. Obtenido de https://ruidera.uclm.es/xmlui/bitstream/handle/10578/9056/Fases\%20y\%20evoluci\%C3\% B3n\%20de\%20la\%20conciencia\%20ortogr\%C3\%A1fica\%20infantil.pdf?sequence=1\&is Allowed $=\mathrm{y}$ 
Equipo de Desarrollo Curricular. (2020). Priorización Curricular Lenguaje y Comunicación / Lengua y Literatura $1^{\circ}$ Básico a $4^{\circ}$ Medio. Santiago de Chile: Unidad de Currículum y Evaluación, Ministerio de Educación del Gobierno de Chile.

Gili Gaya, S (1948). Curso superior de sintaxis española ( $2^{\circ} \mathrm{ed}$.). Bibliograf: Barcelona.

Gutierrez-Clellen, V., y Hofstetter, R. (1994). Syntactic complexity in Spanish narratives: A developmental study. Journal of Speech, Language, and Hearing Research, 37(3). https://doi.org/10.1044/jshr.3703.645645-654

Hasan, R. (1984). The nursery tale as a genre. In Nottingham Linguistic Circular, 13. Nottingham University Press (pp. 71-102).

Loureda, O. (2017). Introducción a la tipología textual. Madrid: Arco/Libros

Matute, E., Chamorro, Y., González, A., Guajardo, S. y Inozemtseva, O. (2014). Aprendizaje de la escritura en niños hispanohablantes. La importancia del estudio de la adquisición de la escritura. En D. Sagástegui, C. Palomar, \& M. Chavoya (Ed.), Paisajes a lo educativo desde la investigación: Libro conmemorativo del xxv aniversario del Departamento de Estudios en Educación de la Universidad de Guadalajara (pp. 49-71). Universidad de Guadalajara.

Meneses, A. y Ow, M. (2016). Desarrollo sintáctico en narraciones y exposiciones orales de estudiantes chilenos a través de la escolaridad: diferentes mediciones de complejidad sintáctica. Estudios de Psicología, http://dx.doi.org/10.1080/02109395.2015.1129824

Meneses, A., Ow, M., y Benítez, R. (2012). Complejidad sintáctica: ¿modalidad comunicativa o tipo textual? Estudio de casos de producciones textuales de estudiantes de $5^{\circ}$ básico. Onomázein, (25), 65-93.

Montealegre, R. y Forero, L. (2006). Desarrollo de la lectoescritura: adquisición y dominio. Acta Colombiana de Psicología, 9(1),25-40.

Ow, M. y Alvarado, C. (2013). Niños que narran: aumento en la complejidad discursiva y sintáctica durante la edad escolar. Literatura y Lingüística, 28, 149-168. http://dx.doi.org/10.4067/S0716-58112013000200009

Pavez, M., Coloma, C. y Maggiolo, M. (2008). El desarrollo narrativo en niños: Una propuesta práctica para la evaluación y la intervención en niños con trastorno del lenguaje. $A R S$ Médica.

Pavez, M., Coloma, C., Araya C., Maggiolo M. y Peñaloza C. (2015). Gramaticalidad y complejidad en narración y conversación en niños con trastorno específico del lenguaje. Revista de Logopedia, Foniatría y Audiología, 35(4), 150-158. http://dx.doi.org/10.1016/j.rlfa.2015.07.004

Peña Galeano, O.Y., y Quintero Saavedra, A.C. (2016). La escritura como práctica situada en el primer ciclo: promoción de procesos cognitivos y metacognitivos. Cuadernos de Lingüística Hispánica, (28), 189-206.

http://dx.doi. org/10.19053/0121053X.4915

Peñaloza, C. (2008). Producción de oraciones complejas por niños de 6, 8 y 10 años en la actividad discursiva de recontado narrativo [Tesis de magister]. Pontificia Universidad Católica de Chile.

Peñaloza, C., Araya, C. y Coloma, C. J. (2017). Desarrollo de la complejidad sintáctica en recontados narrativos de niños preescolares y escolares. Logos: Revista de Lingüística, Filosofía y Literatura 27(2), 333-348.

http://dx.doi.org/10.15443/RL2726 
Pozo, S. (2010). El desarrollo caligráfico para la consolidación de la escritura en los alumnos de educación primaria multigrado. Cinzontle, 4, 31-35.

R Core Team. (2020). R: A language and environment for statistical computing. $R$ Foundation for Statistical Computing. Vienna, Austria [https://www.R-project.org/].

Real Academia Española. (2010). Nueva gramática de la lengua española. Ciudad de México: Editorial Planeta Mexicana.

Rubio, M. (2016). Narraciones de escolares básicos: dos tareas de escritura. Literatura y Lingüística (34), 221-244. Obtenido de https://scielo.conicyt.cl/pdf/lyl/n34/art11.pdf http://dx.doi.org/10.4067/S0716-58112016000200011.

Rubio, M (2019). Procesos experienciales en narraciones sobre situaciones cotidianas escritas por $\begin{array}{llll}\text { escolares } & \text { básicos. } & \text { Signos }\end{array}$ http://dx.doi.org/10.4067/S0718-09342019000100158

Rubio, M (2020). Análisis clausular de dos tipos de narraciones escritas por estudiantes de $\begin{array}{llllll}\text { educación } & \text { básica. } & \text { Árboles } & \text { y } & \text { Rizomas } & \text { 69-87. }\end{array}$ https://doi.org/10.35588/ayr.v2i2.4539

Salgado, H. (1997). Aprendizaje ortográfico en la didáctica de la escritura. Buenos Aires, Aique.

Sánchez, V., Moyano, V. y Borzone, A. (2011). Demandas cognitivas de la escritura: comparación de dos situaciones de producción. Estudios Pedagógicos, 37(1), 227-236. http://dx.doi.org/10.4067/S0718-07052011000100012

Smith-Lock, K., Nickels, L. y Mortensen, L. (2009). Story writing skills of adults with a history language-impairment. Reading and Writing, 22, 713-734.

https://doi.org/10.1007/s11145-008-9138-6

Sotomayor, C., Lucchini, G., Bedwell, P., Biedma, M., Hernández, C. y Molina, D. (2013). Producción escrita en la Educación Básica: análisis de narraciones de alumnos de escuelas municipales de Chile. Onomázein, (27), 53-77.

Solano, O., Ramírez, A., Bartolo, F., Giraldo, O. y Salinas, A. (2007). Análisis de Diagnóstico en el Modelo de Regresión Logística: Una aplicación. Pesquimat, 10(1), 55-70.

https://doi.org/10.15381/pes.v10i1.9431

Subsecretaría de Educación Parvularia. (2018). Bases Curriculares de la Educación Parvularia. Santiago de Chile: Ministerio de Educación del Gobierno de Chile, ISBN 978-956-292706-2.

Vygotsky, L. S. (1995). Historia del desarrollo de las funciones psicológicas superiores. En Obras Escogidas II. Madrid, España: Visor. (Año de publicación del original: 1931). 